\title{
The influence of preoperative spinal sagittal balance on clinical outcomes after microendoscopic laminotomy in patients with lumbar spinal canal stenosis
}

\author{
Sho Dohzono, MD, PhD, ${ }^{1}$ Hiromitsu Toyoda, MD, PhD, ${ }^{1}$ Tomiya Matsumoto, MD, PhD, ${ }^{2}$ \\ Akinobu Suzuki, MD, PhD, ${ }^{1}$ Hidetomi Terai, MD, PhD, ${ }^{1}$ and Hiroaki Nakamura, MD, PhD1 \\ 1Department of Orthopaedic Surgery, Osaka City University Graduate School of Medicine; and 2Department of Orthopaedic \\ Surgery, Osaka Rosai Hospital, Osaka, Japan
}

\begin{abstract}
OBJECT More information about the association between preoperative anterior translation of the C-7 plumb line and clinical outcomes after decompression surgery in patients with lumbar spinal canal stenosis (LSS) would help resolve problems for patients with sagittal imbalance. The authors evaluated whether preoperative sagittal alignment of the spine affects low-back pain and clinical outcomes after microendoscopic laminotomy.

METHODS This study was a retrospective review of prospectively collected surgical data. The study comprised 88 patients with LSS (47 men and 41 women) who ranged in age from 39 to 86 years (mean age 68.7 years). All patients had undergone microendoscopic laminotomy at Osaka City University Graduate School of Medicine from May 2008 through October 2012. The minimum duration of clinical and radiological follow-up was 6 months. All patients were evaluated by Japanese Orthopaedic Association (JOA) and visual analog scale (VAS) scores for low-back pain, leg pain, and leg numbness before and after surgery. The distance between the C-7 plumb line and the posterior corner of the sacrum (sagittal vertical axis [SVA]) was measured on lateral standing radiographs of the entire spine obtained before surgery. Radiological factors and clinical outcomes were compared between patients with a preoperative SVA $\geq 50 \mathrm{~mm}$ (forwardbending trunk [F] group) and patients with a preoperative SVA $<50 \mathrm{~mm}$ (control [C] group). A total of 35 patients were allocated to the $\mathrm{F}$ group ( 19 male and 16 female) and 53 to the $C$ group ( 28 male and 25 female).
\end{abstract}

RESULTS The mean SVA was $81.0 \mathrm{~mm}$ for patients in the $\mathrm{F}$ group and $22.0 \mathrm{~mm}$ for those in the $\mathrm{C}$ group. At final followup evaluation, no significant differences between the groups were found for the JOA score improvement ratio $(73.3 \%$ vs $77.1 \%$ ) or the VAS score for leg numbness (23.6 vs $24.0 \mathrm{~mm}$ ); the VAS score for low-back pain was significantly higher for those in the $\mathrm{F}$ group $(21.1 \mathrm{~mm})$ than for those in the $\mathrm{C}$ group $(11.0 \mathrm{~mm})$; and the VAS score for leg pain tended to be higher for those in the $\mathrm{F}$ group $(18.9 \pm 29.1 \mathrm{~mm})$ than for those in the $\mathrm{C}$ group $(9.4 \pm 16.0 \mathrm{~mm})$.

CONCLUSIONS Preoperative alignment of the spine in the sagittal plane did not affect JOA scores after microendoscopic laminotomy in patients with LSS. However, low-back pain was worse for patients with preoperative anterior translation of the C-7 plumb line than for those without.

http://thejns.org/doi/abs/10.3171/2014.11.SPINE14452

KEY WORDS microendoscopic lumbar decompression; sagittal vertical axis; C-7 plumb line; low-back pain

$\mathrm{L}$ UMBAR spinal canal stenosis (LSS) is a common problem among older adults and is a cause of leg pain and low-back pain. Standing and bending backward can worsen symptoms, and symptoms are relieved by standing and flexing. ${ }^{16}$ Alignment of the spine in the sagittal plane (spinal sagittal balance) is taken into consideration in the management of lumbar diseases and low-back pain, ${ }^{1,8,9}$ and deviation of the $\mathrm{C}-7$ plumb line from the posterior corner of the sacrum is correlated with health-related quality of life. ${ }^{6,13}$

We speculated that preoperative spinal alignment could be closely associated with severity of symptoms and could affect clinical outcomes after surgery. At the Osaka City University Graduate School of Medicine, minimally in-

ABBREVIATIONS JOA = Japanese Orthopaedic Association; LSS = lumbar spinal canal stenosis; SVA = sagittal vertical axis; VAS = visual analog scale SUBMITTED May 4, 2014. ACCEPTED November 4, 2014.

INCLUDE WHEN CITING Published online April 3, 2015; DOI: 10.3171/2014.11.SPINE14452.

DISCLOSURE The authors report no conflict of interest concerning the materials or methods used in this study or the findings specified in this paper. 
vasive microendoscopic laminotomy is performed for the treatment of LSS. Unlike the traditional open laminectomy, this procedure can effectively achieve neural decompression without excessive removal of the posterior stabilizing structures. The degree of low-back pain after surgery is generally mild. ${ }^{7}$ The purpose of this study was to evaluate whether preoperative spinal sagittal balance affects low-back pain and clinical outcomes after microendoscopic laminotomy for LSS.

\section{Methods \\ Patients}

This study was a retrospective review of prospectively collected surgical data. For this study, 5 authors (S.D., H. Toyoda, A.S., H. Terai, and H.N.) retrospectively reviewed the records of 93 patients with a diagnosis of LSS who had consecutively undergone microendoscopic laminotomy from May 2008 through October 2012. The minimum of clinical and radiological follow-up time was 6 months. Mean symptom duration before surgery was 3.3 years (range 4 months-20 years), and patients were observed for a mean duration of 16 months after surgery (range 6-48 months). Of the 93 patients who were considered for inclusion in the analysis, 5 were excluded because they had previously undergone spinal surgery $(n=4)$ or had a vertebral fracture $(\mathrm{n}=1)$. We included the remaining 88 patients (47 male and 41 female), whose mean age was 68.7 years (range $39-86$ years), in the analysis.

All 88 patients had experienced lower-extremity pain and/or numbness, 45 patients were severely limited in the distance they could walk $(<100 \mathrm{~m}), 35$ patients had decreased muscle strength in one or both of the lower extremities, and 6 patients had urinary dysfunction. LSS was categorized as cauda equina type for 9 patients, radicular type for 15 patients, and mixed type for 54 patients. Degenerative spondylolisthesis $(>3 \mathrm{~mm})$ was present in 36 patients, and scoliotic disc wedging $\left(>3^{\circ}\right)$ was present at the affected level in 17 patients. Exclusion criteria for use of this surgical procedure in patients with degenerative spondylolisthesis were anterior slippage greater than $25 \%$ and segmental kyphosis in flexion greater than $5^{\circ}$. Exclusion criteria for use of this surgical procedure in patients with degenerative lumbar scoliosis were as follows: 1) Cobb angle greater than $25^{\circ}$, 2) severe low-back pain, 3) changes in segmental disc wedging between standing and prone position greater than $5^{\circ}$, and 4) lateral disc slippage greater than $3 \mathrm{~mm}$. Diabetes was documented for $14 \mathrm{pa}-$ tients (controlled by insulin for 3 patients); and other internal diseases such as hypertension, ischemic heart disease, and chronic renal disorder were reported for 62 patients. The American Society of Anesthesiologists physical status was Class I for 17 patients, Class II for 66 patients, and Class III for 5 patients.

A total of 79 patients underwent decompression at a single level (68 patients at L4-5, 8 at L3-4, 2 at L5-6, and 1 at L5-S1), and 9 patients underwent decompression at 2 levels (7 patients at L3-5, 1 at L2-4, and 1 at L4-S1).

Patients were divided into 2 groups according to the sagittal vertical axis (SVA): a forward-bending trunk group (F group; SVA $\geq 50 \mathrm{~mm}$ ) and a control group (C group; SVA $<50 \mathrm{~mm}$; see Fig. 2). A total of 35 patients were allocated to the F group (19 male and 16 female), and 53 were allocated to the $\mathrm{C}$ group ( 28 male and 25 female).

\section{Surgical Procedure}

All patients underwent bilateral decompression via a unilateral approach to decompress the central canal and bilateral lateral recesses performed by using the METRx Microendoscopic Discectomy System (Medtronic Sofamor Danek) as described by Toyoda et al. ${ }^{18}$ After the level was confirmed under fluoroscopic guidance, an 18$\mathrm{mm}$ skin incision was made on the approach side. The endoscope was attached to an $18-\mathrm{mm}$ tubular retractor. Laminotomy was performed on the approach side by use of a Kerrison rongeur air drill and an osteotome. Decompression was then performed on the contralateral side after tilting of the tubular retractor (Fig. 1).

\section{Clinical Evaluations}

Surgical outcomes were evaluated by using the Japanese Orthopaedic Association (JOA) score for low-back pain, which consists of 4 categories and has a maximum score of 29 points (Table 1). The JOA score improvement ratio (\%) was calculated as follows: (postoperative JOA score - preoperative JOA score)/(29 - preoperative JOA score $) \times 100$. JOA score and visual analog scale (VAS) ratings of low-back pain, leg pain, and leg numbness were determined before surgery and at the final follow-up evaluation. The VAS score for pain or numbness intensity ranged from 0 to $100 \mathrm{~mm}$ and was anchored by "no pain or numbness" (score of 0 ) and "worst imaginable pain or numbness" (score of 100). These data were collected at the standardized times of 6 months, 1 year, and 2 years after surgery.

\section{Radiological Evaluations}

Images were assessed by 3 authors (S.D., H. Toyoda, and T.M.), who were blinded to outcomes. By using lateral standing films of the entire spine obtained before surgery, as described by Jackson and McManus, ${ }^{8}$ they measured the distance between the C-7 plumb line and the posterior corner of the sacrum (the SVA; Fig. 2), the angle between
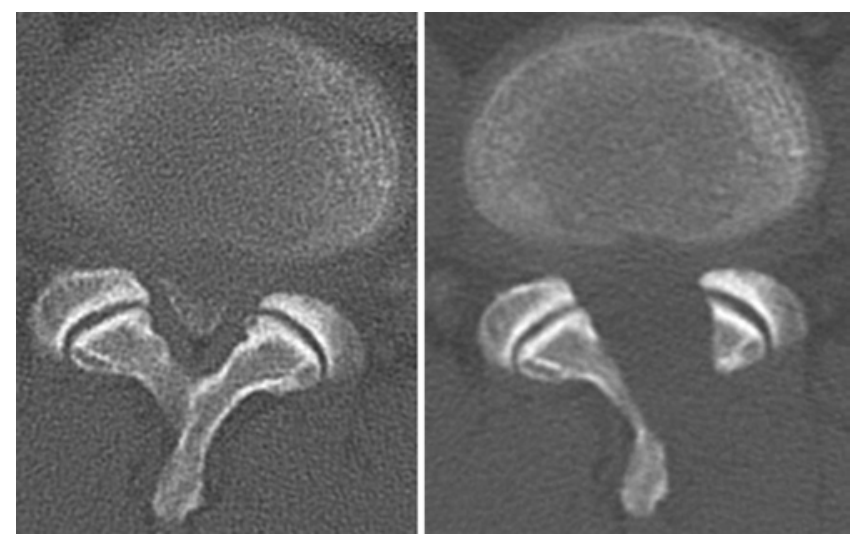

FIG. 1. Axial CT images before surgery (left) and 1 week after microendoscopic bilateral decompression via a unilateral approach (right). The lumbar spinal canal was adequately decompressed on the contralateral side as well as the approach side. 
TABLE 1. Summary of the JOA scoring system for evaluation of low-back pain*

\begin{tabular}{lc}
\hline \multicolumn{1}{c}{ Sign or Symptom } & Points \\
\hline Subjective symptom & 9 \\
\hline Low-back pain & \\
\hline Leg pain \&/or tingling & 6 \\
\hline Gait distance & \\
\hline Clinical signs & \\
\hline $\begin{array}{l}\text { Abnormal response to straight-leg raising test (including } \\
\quad \text { tight hamstrings) }\end{array}$ \\
\hline $\begin{array}{l}\text { Sensory disturbance } \\
\quad \text { Motor disturbance }\end{array}$ \\
\hline Restriction of activities of daily living \\
\hline Abnormal urinary bladder function & -3 to -6 \\
\hline
\end{tabular}

* Maximum score possible $=29$ points. Improvement ratio $(\%)=$ (postoperative - preoperative score)/(29 - preoperative score $) \times 100$.

the upper margin of L-1 and S-1, sacral slope, pelvic tilt, and pelvic incidence (Fig. 3).

\section{Statistical Analysis}

Radiological factors and clinical outcomes were statistically compared between the 2 groups by using the Student t-test or the Mann-Whitney U-test for continuous
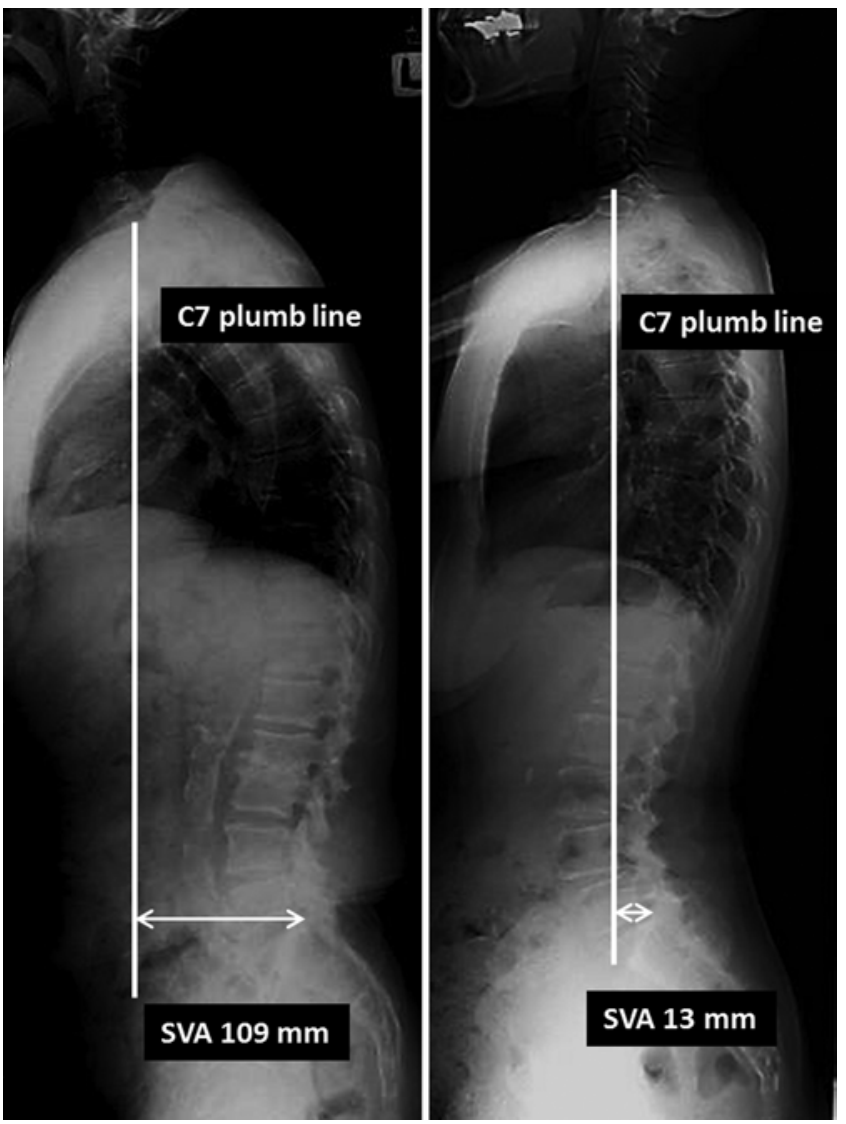

FIG. 2. Representative lateral standing whole-spine radiographs. Left: Patient in the $\mathrm{F}$ group. Right: Patient in the $\mathrm{C}$ group.

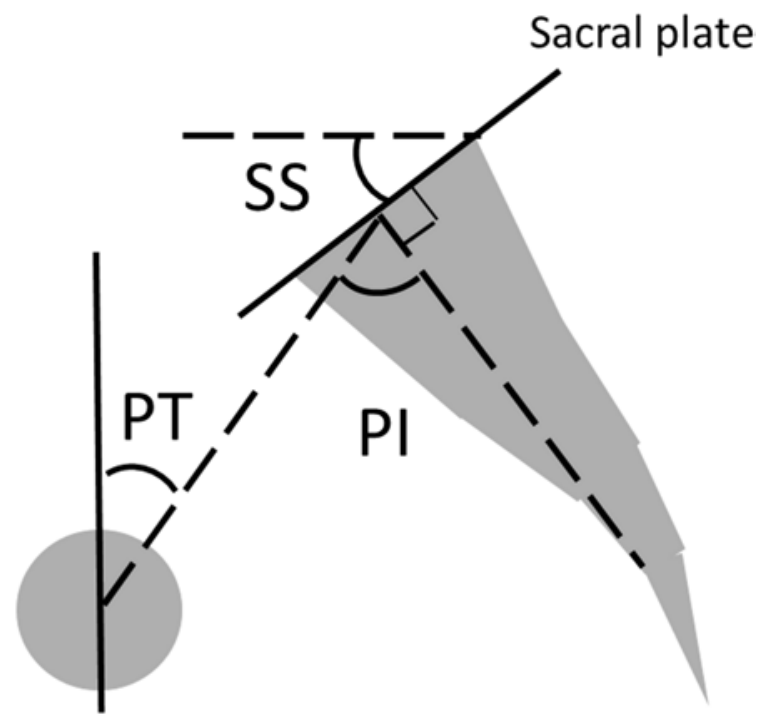

\section{Femoral heads axis}

FIG. 3. Diagram showing measurements used in evaluating spinal radiographs. Sacral slope (SS) was defined as the angle between the horizontal and the sacral plate. Pelvic tilt (PT) was defined as the angle between the vertical line and the line connecting the midpoint of the sacral plate to the femoral heads axis. Pelvic incidence (PI) was defined as the angle between the line perpendicular to the sacral plate at its midpoint and the line connecting this point to the femoral heads axis.

variables and the chi-square test for categorical variables. Correlations between SVA and preoperative and postoperative VAS scores for low-back pain were analyzed by using the Pearson correlation. All statistical analyses were performed by using IBM SPSS Statistics for Windows, version 19 (IBM Corp.). A p value $<0.05$ was considered statistically significant.

\section{Results}

Demographic characteristics of the patients are shown in Table 2. At the time of surgery, the age of patients in the F group (mean 71.1 years, range $45-86$ years) tended to be lower than that of patients in the C group (mean 67.1 years, range $52-82$ years; $p=0.058$ ). However, no significant differences were found between the groups in terms of sex, duration of symptoms, duration of operation per vertebral level, blood loss per level, or number of decompression levels. The mean SVA was $81.0 \mathrm{~mm}$ (range $51-170 \mathrm{~mm}$ ) for patients in the F group and $22.0 \mathrm{~mm}$ (range -43 to $49 \mathrm{~mm}$ ) for patients in the C group. The L1-S1 angle for patients in the $\mathrm{F}$ group (mean $22.9^{\circ}$, range $-18^{\circ}$ to $43^{\circ}$ ) was significantly lower than that for those in the $\mathrm{C}$ group (mean $32.8^{\circ}$, range $-11^{\circ}$ to $58^{\circ} ; \mathrm{p}=0.001$ ). However, no significant between-group differences were found for sacral slope, pelvic tilt, and pelvic incidence angle.

There were 3 patients in the $\mathrm{F}$ group and 2 patients in the $\mathrm{C}$ group with a dural tear, and 2 of the 5 patients had transient neurological deterioration. One patient experienced neurological complications on the contralateral side, which included mild paresthesia and a decrease in muscle strength. 


\section{Clinical Results}

Some of the mean values are presented $\pm \mathrm{SD}$. The mean preoperative VAS score for low-back pain was $50.4 \pm 29.8$ $\mathrm{mm}$ for patients the F group and $42.0 \pm 31.5 \mathrm{~mm}$ for those the $\mathrm{C}$ group; the mean preoperative VAS score for leg pain was $57.7 \pm 30.4 \mathrm{~mm}$ for patients in the F group and $60.0 \pm$ $28.1 \mathrm{~mm}$ for those in the C group; and the mean preoperative VAS score for leg numbness was $42.8 \pm 27.8 \mathrm{~mm}$ for patients in the F group and $55.2 \pm 29.2 \mathrm{~mm}$ for those in the $\mathrm{C}$ group. These values did not differ significantly between the groups. However, preoperative JOA scores tended to be lower for patients in the F group (mean 12.9, range 3-21) than for those in the $\mathrm{C}$ group (mean 14.7, range 6-22; $\mathrm{p}=$ $0.054)$.

At the final follow-up evaluation, the mean JOA score was 24.5 for patients in the F group and 25.7 for those in the $\mathrm{C}$ group, and the JOA score improvement ratio was $73.3 \%$ for patients in the F group and $77.1 \%$ for those the $\mathrm{C}$ group (not significantly different, $\mathrm{p}=0.364$ ) (Fig. 4). Also at the final follow-up evaluation, the VAS score for low-back pain was higher for patients in the F group (21.0 $\pm 24.4 \mathrm{~mm})$ than for those in the $C$ group $(11.0 \pm 16.6 \mathrm{~mm}$; $\mathrm{p}=0.044$ ), and the VAS score for leg pain tended to be higher for patients in the $\mathrm{F}$ group $(18.9 \pm 29.1 \mathrm{~mm})$ than for those in the $C$ group $(9.4 \pm 16.0 \mathrm{~mm} ; \mathrm{p}=0.055)$ (Fig. $5)$. There was a positive correlation between preoperative SVA and preoperative VAS scores for low-back pain and between preoperative SVA and VAS scores for low-back pain at the final follow-up evaluation (Fig. 6). At the final follow-up evaluation, the VAS score for leg numbness was $23.6 \pm 29.6 \mathrm{~mm}$ for patients in the F group and $24.0 \pm 25.4$ $\mathrm{mm}$ for those in the $\mathrm{C}$ group; this difference was not statistically significant.

TABLE 2. Demographic data and preoperative clinical characteristics

\begin{tabular}{|c|c|c|c|}
\hline Variable & $\begin{array}{l}\text { F Group } \\
(n=35)\end{array}$ & $\begin{array}{l}\text { C Group } \\
(n=53)\end{array}$ & $\begin{array}{c}p \\
\text { Value }\end{array}$ \\
\hline SVA $(m m)^{*}$ & $81.0 \pm 27.0$ & $22.0 \pm 18.2$ & \\
\hline $\operatorname{Sex}(M / F)$ & $19 / 16$ & $28 / 25$ & 0.893 \\
\hline Age $(y r s)^{*}$ & $71.1 \pm 10.9$ & $67.1 \pm 8.6$ & 0.058 \\
\hline Symptom duration (mos) $)^{*}$ & $39.2 \pm 35.2$ & $42.6 \pm 49.8$ & 0.728 \\
\hline Operation time/level (mins)* & $172.5 \pm 50.3$ & $166.6 \pm 44.9$ & 0.671 \\
\hline Blood loss per level $(\mathrm{g})^{*}$ & $63.2 \pm 54.2$ & $64.5 \pm 87.3$ & 0.856 \\
\hline \multicolumn{4}{|l|}{ Vertebral level (no. of patients) } \\
\hline L-1 & 32 & 47 & \multirow{3}{*}{0.323} \\
\hline L-2 & 2 & 6 & \\
\hline L-3 & 1 & 0 & \\
\hline L1-S1 angle $\left({ }^{\circ}\right)^{*}$ & $22.9 \pm 15.5$ & $32.8 \pm 12.6$ & 0.001 \\
\hline Sacral slope $\left({ }^{\circ}\right)^{*}$ & $32.9 \pm 8.4$ & $34.3 \pm 8.3$ & 0.422 \\
\hline Pelvic tilt $\left({ }^{\circ}\right)^{*}$ & $22.3 \pm 10.0$ & $20.0 \pm 8.1$ & 0.229 \\
\hline Pelvic incidence $\left({ }^{\circ}\right)^{*}$ & $55.1 \pm 9.5$ & $53.9 \pm 9.7$ & 0.564 \\
\hline JOA score (points)* & $12.7 \pm 4.0$ & $14.7 \pm 3.7$ & 0.054 \\
\hline VAS for low-back pain $(\mathrm{mm})^{*}$ & $50.4 \pm 29.8$ & $42.0 \pm 31.5$ & 0.216 \\
\hline VAS for leg pain $(\mathrm{mm})^{\star}$ & $57.7 \pm 30.4$ & $60.0 \pm 28.1$ & 0.707 \\
\hline VAS for leg numbness $(\mathrm{mm})^{*}$ & $42.8 \pm 27.8$ & $55.2 \pm 29.2$ & 0.051 \\
\hline
\end{tabular}

* Presented as the mean \pm SD.

\section{Discussion}

Microendoscopic laminotomy is a modification of microscopic bilateral decompression via a unilateral approach. This procedure is widely performed and reportedly provides good clinical outcomes.,10,12 It has several advantages over the microsurgical procedure for the posterior soft tissues; it is minimally invasive to the paraspinal muscles because the tubular retractor enables gentle tissue dissection and minimizes retraction of the paraspinal muscles. Mayer et al. ${ }^{11}$ reported decreased paraspinal muscle strength and atrophy after extensive muscle retraction during open decompression. Ikuta et al. ${ }^{7}$ demonstrated that in patients with LSS, creatine kinase recovered to preoperative levels within 1 week of microendoscopic laminotomy and that the degree of low-back pain after surgery was mild.

The advantages of microendoscopic laminotomy are maximal preservation of structural components such as midline structures, facet joints, and paravertebral muscle and enlargement of the central parts of the spinal canal. Therefore, the radiographic changes that occur after this procedure are similar to those that occur naturally in the course of LSS. From this point of view, clinical outcomes after this procedure could provide useful information about the pathology of LSS. In our study, VAS scores for low-back pain improved significantly after microendoscopic laminotomy, more so for patients without forwardbending trunk posture before surgery (controls) than for patients with forward-bending trunk posture. Furthermore, preoperative SVA correlated with both preoperative and postoperative VAS scores for low-back pain. We speculate that neural compression was the main cause of low-back pain for the LSS patients in this study and that preoperative sagittal parameters, as determined radiographically, strongly affected residual postoperative lowback pain.

Abnormal spinal alignment in the sagittal plane during standing is influenced by decreased paraspinal muscle strength resulting from aging and any accompanying decrease in spinal mobility. Takemitsu et al. ${ }^{17}$ described how continuous extension of the paraspinal muscles caused by

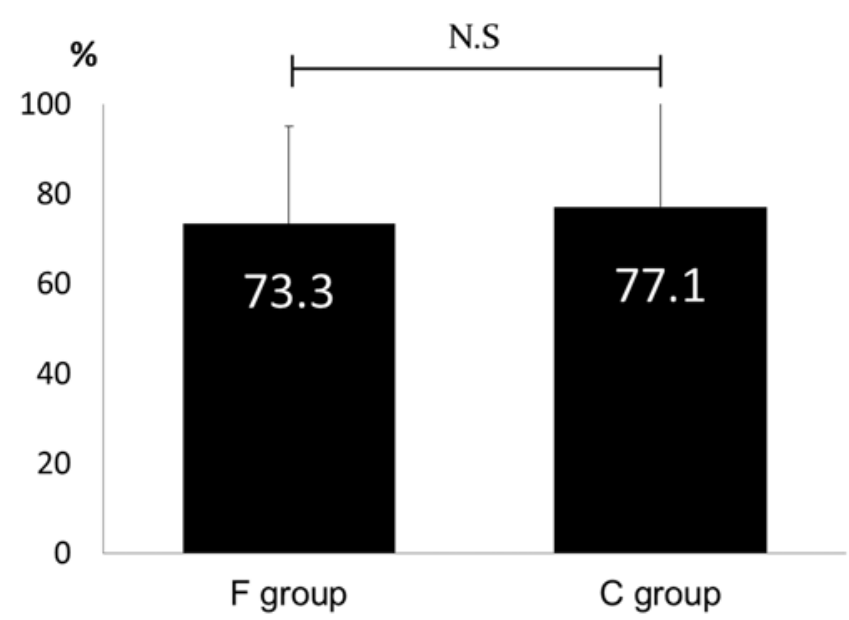

FIG. 4. Improvement ratio of JOA scores among patients in both groups at final follow-up evaluation $(p=0.128)$. N.S = not significant. 


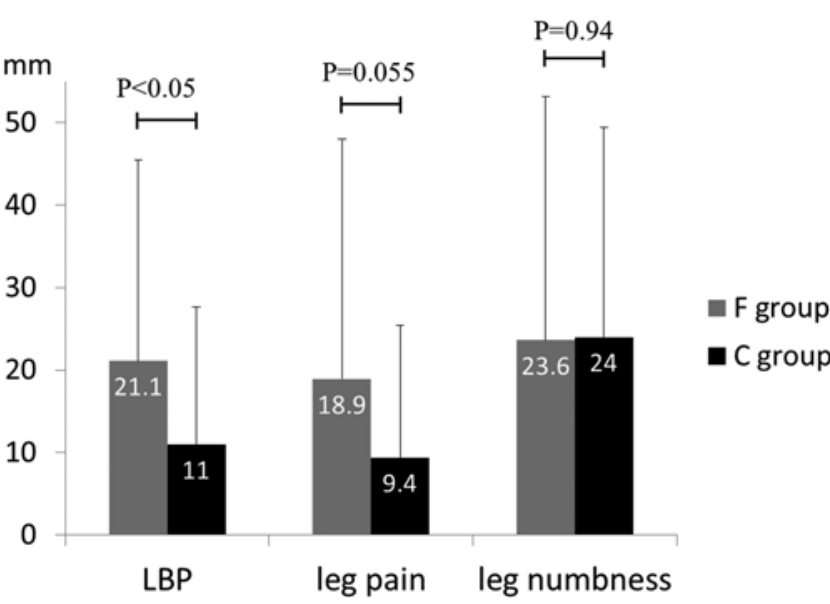

FIG. 5. Bar graphs showing VAS scores for low-back pain (LBP), leg pain, and leg numbness among patients in both groups at final follow-up evaluation. Error bars indicate standard deviation.

long-term forward-bending posture increases the pressure on those muscles and promotes local ischemia. Schwab et al. ${ }^{13}$ reported that reduction of SVA to $<50 \mathrm{~mm}$ brought the C-7 plumb line behind the femoral heads to relieve the complaint of falling forward and that it improved quality of life. Several studies have shown that positive sagittal balance is correlated with adverse health status outcomes among adults with uncorrected spinal deformity. ${ }^{5,6}$

Previous studies have reported that a more forward SVA with loss of lumbar lordosis is positively correlated with age. ${ }^{4}$ In our study, pelvic parameters such as sacral slope, pelvic tilt, or pelvic incidence angle were similar between groups. However, we found that patients with preoperative forward-bending trunk posture had significantly less lumbar lordosis and tended to be of older age and to have a lower preoperative JOA score than did patients without preoperative forward-bending trunk posture. This finding supports the results of other studies. Suzuki et al. ${ }^{15}$ reported a correlation between SVA and JOA scores among patients with LSS, and Endo et al. ${ }^{2}$ reported a correlation between SVA and JOA scores among patients with lumbar disc herniation. However, in our study, JOA score improvement ratio and postoperative VAS scores for leg pain and leg numbness were similar among patients with and without preoperative forward-bending trunk posture. Therefore, microendoscopic laminotomy for LSS is useful even for patients with forward-bending trunk posture.

Many factors have been identified as risk factors for low-back pain, including body mass index, age, sex, and spinal sagittal balance. ${ }^{8,14,19}$ Unfortunately, despite many clinical studies, the strength of the associations between these factors and low-back pain remains inconclusive. Enomoto et al. ${ }^{3}$ reported that patients with lumbar kyphosis had more activity in the lower-back muscles when in a standing position and more muscle fatigue in the upper lumbar spine region than did patients with LSS. From the results of our study of microendoscopic laminotomy in patients with LSS, we speculate that neural compression and abnormal translation of SVA are possible causes of low-back pain in patients with LSS.
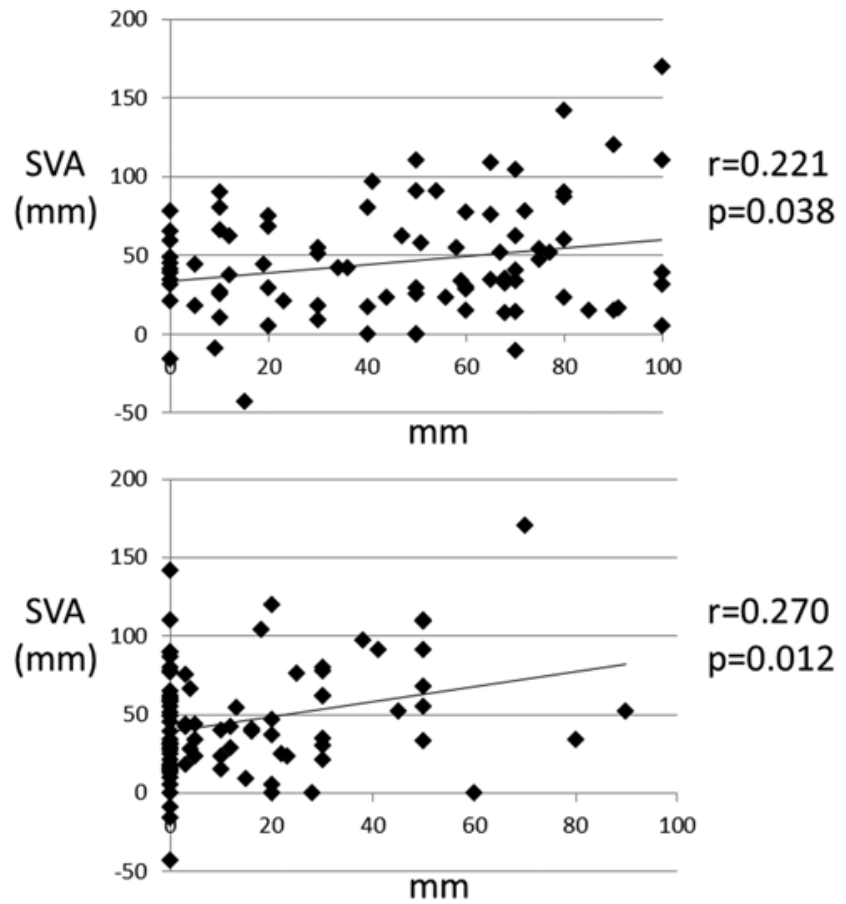

FIG. 6. Correlation between SVA and VAS scores for low-back pain before surgery (upper) and at final follow-up evaluation (lower).

Our study has several limitations. First, the minimum follow-up period of 6 months was short for the treatment of degenerative LSS. Second, we did not show the postoperative SVA. Further research into SVA change after lumbar decompression might be needed.

To the best of our knowledge, ours is the first study to examine the association between preoperative alignment of the spine in the sagittal plane and clinical outcomes after microendoscopic laminotomy in patients with LSS. Microendoscopic surgery itself is minimally invasive to the paraspinal muscles. However, preoperative abnormal translation of SVA was associated with residual low-back pain after this procedure.

\section{Conclusions}

Among patients with LSS, alignment of the spine in the sagittal plane did not affect JOA scores after microendoscopic laminotomy. However, low-back pain was worse for patients with preoperative anterior translation of the C-7 plumb line than for those without.

\section{References}

1. Barrey C, Jund J, Noseda O, Roussouly P: Sagittal balance of the pelvis-spine complex and lumbar degenerative diseases. A comparative study about 85 cases. Eur Spine J 16:14591467, 2007

2. Endo K, Suzuki H, Tanaka H, Kang Y, Yamamoto K: Sagittal spinal alignment in patients with lumbar disc herniation. Eur Spine J 19:435-438, 2010

3. Enomoto M, Ukegawa D, Sakaki K, Tomizawa S, Arai Y, Kawabata S, et al: Increase in paravertebral muscle activity in lumbar kyphosis patients by surface electromyography compared with lumbar spinal canal stenosis patients and 
healthy volunteers. J Spinal Disord Tech 25:E167-E173, 2012

4. Gelb DE, Lenke LG, Bridwell KH, Blanke K, McEnery KW: An analysis of sagittal spinal alignment in 100 asymptomatic middle and older aged volunteers. Spine (Phila Pa 1976) 20:1351-1358, 1995

5. Glassman SD, Berven S, Bridwell K, Horton W, Dimar JR: Correlation of radiographic parameters and clinical symptoms in adult scoliosis. Spine (Phila Pa 1976) 30:682-688, 2005

6. Glassman SD, Bridwell K, Dimar JR, Horton W, Berven S, Schwab F: The impact of positive sagittal balance in adult spinal deformity. Spine (Phila Pa 1976) 30:2024-2029, 2005

7. Ikuta K, Arima J, Tanaka T, Oga M, Nakano S, Sasaki K, et al: Short-term results of microendoscopic posterior decompression for lumbar spinal stenosis. Technical note. J Neurosurg Spine 2:624-633, 2005

8. Jackson RP, McManus AC: Radiographic analysis of sagittal plane alignment and balance in standing volunteers and patients with low back pain matched for age, sex, and size. A prospective controlled clinical study. Spine (Phila Pa 1976) 19:1611-1618, 1994

9. Jang JS, Lee SH, Kim JM, Min JH, Han KM, Maeng DH: Can patients with sagittally well-compensated lumbar degenerative kyphosis benefit from surgical treatment for intractable back pain? Neurosurgery 64:115-121, 2009

10. Khoo LT, Fessler RG: Microendoscopic decompressive laminotomy for the treatment of lumbar stenosis. Neurosurgery 51 (5 Suppl):S146-S154, 2002

11. Mayer TG, Vanharanta H, Gatchel RJ, Mooney V, Barnes D, Judge L, et al: Comparison of CT scan muscle measurements and isokinetic trunk strength in postoperative patients. Spine (Phila Pa 1976) 14:33-36, 1989

12. Pao JL, Chen WC, Chen PQ: Clinical outcomes of microendoscopic decompressive laminotomy for degenerative lumbar spinal stenosis. Eur Spine J 18:672-678, 2009

13. Schwab F, Patel A, Ungar B, Farcy JP, Lafage V: Adult spinal deformity-postoperative standing imbalance: how much can you tolerate? An overview of key parameters in assessing alignment and planning corrective surgery. Spine (Phila Pa 1976) 35:2224-2231, 2010

14. Shiri R, Solovieva S, Husgafvel-Pursiainen K, Taimela S,
Saarikoski LA, Huupponen R, et al: The association between obesity and the prevalence of low back pain in young adults: the Cardiovascular Risk in Young Finns Study. Am J Epidemiol 167:1110-1119, 2008

15. Suzuki H, Endo K, Kobayashi H, Tanaka H, Yamamoto K: Total sagittal spinal alignment in patients with lumbar canal stenosis accompanied by intermittent claudication. Spine (Phila Pa 1976) 35:E344-E346, 2010

16. Takahashi K, Miyazaki T, Takino T, Matsui T, Tomita K: Epidural pressure measurements. Relationship between epidural pressure and posture in patients with lumbar spinal stenosis. Spine (Phila Pa 1976) 20:650-653, 1995

17. Takemitsu Y, Harada Y, Iwahara T, Miyamoto M, Miyatake Y: Lumbar degenerative kyphosis. Clinical, radiological and epidemiological studies. Spine (Phila Pa 1976) 13:13171326,1988

18. Toyoda H, Nakamura H, Konishi S, Dohzono S, Kato M, Matsuda H: Clinical outcome of microsurgical bilateral decompression via unilateral approach for lumbar canal stenosis: minimum five-year follow-up. Spine (Phila Pa 1976) 36:410-415, 2011

19. van Tulder MW, Koes BW, Bouter LM: Conservative treatment of acute and chronic nonspecific low back pain. A systematic review of randomized controlled trials of the most common interventions. Spine (Phila Pa 1976) 22:21282156, 1997

\section{Author Contributions}

Conception and design: Toyoda, Dohzono. Acquisition of data: Toyoda, Dohzono, Matsumoto. Analysis and interpretation of data: Dohzono. Critically revising the article: all authors. Reviewed submitted version of manuscript: all authors. Approved the final version of the manuscript on behalf of all authors: Toyoda. Statistical analysis: Dohzono. Administrative/technical/ material support: Toyoda. Study supervision: Nakamura.

\section{Correspondence}

Hiromitsu Toyoda, Department of Orthopaedic Surgery, Osaka City University Graduate School of Medicine, 1-4-3 Asahimachi, Abeno-ku, Osaka 545-8585, Japan. email: h-toyoda@msic.med. osaka-cu.ac.jp. 